\title{
Transcatheter Closure of an Aortic-right Ventricular Fistula with an Amplatzer Duct Occluder II (ADO II)
}

\author{
Kanjarut Wongwaitaweewong, M.D., Supaporn Roymanee, M.D., Jirayut Jarutach, M.D. \\ Department of Pediatrics, Faculty of Medicine, Prince of Songkla University, Hat Yai, Songkhla 90110, Thailand. \\ Received 5 September 2019 • Revised 12 April 2020 • Accepted 13 April 2020 • Published online 29 May 2020
}

\begin{abstract}
:
The treatment of choice for an aortic-right ventricular fistula is surgical repair; however, transcatheter treatment of left to right shunt using an occluding device has recently increased. We report a 12-year-old boy who weighed 45 kilograms and presented with an asymptomatic heart murmur. He was diagnosed with aortic-right ventricular fistula. Color Doppler echocardiography revealed a 3-millimeter aortic-right ventricular fistula that was $5 \mathrm{~mm}$ from the right coronary artery, left to right flow, pressure gradient of 100 millimeters of mercury $(\mathrm{mmHg})$; good left ventricle function, ejection fraction of $70.0 \%$, and right ventricular systolic pressure of $40 \mathrm{mmHg}$ (SBP $120 \mathrm{mmHg}$ ) with a normal coronary artery pattern. He successfully underwent transcatheter closure using an Amplatzer Duct Occluder II with transesophageal echocardiography and fluoroscopy guidance.
\end{abstract}

Keywords: Amplatzer Duct Occluder II, aortic-right ventricular fistula, transcatheter closure

Contact: Kanjarut Wongwaitaweewong, M.D.

Department of Pediatrics, Faculty of Medicine, Prince of Songkla University, Hat Yai, Songkhla 90110, Thailand.

E-mail: jahkanjarut@gmail.com

.

This is an open access article under the CC BY-NC-ND license

(http://www.jhsmr.org/index.php/jhsmr/about/editorialPolicies\#openAccessPolicy). 


\section{Introduction}

Aortic-right ventricular fistula is a rare anomaly in heart disease and may be the result of bacterial endocarditis, ruptured sinus of Valsalva, trauma, ${ }^{1}$ or a complication after transcatheter aortic valve implantation. ${ }^{2}$ We report an asymptomatic child who presented exclusively with a continuous murmur and was diagnosed with aortic-right ventricular fistula. The treatment of choice for a fistula is surgical repair but recently the transcatheter treatment of left to right shunts by an occluding device is increasing.

\section{Case report}

A 12-year-old boy who weighed 45 kilogram presented with an asymptomatic heart murmur. He had no history of recurrent pneumonia or dyspnoea on exertion but had bounding pulse, left ventricle (LV) heaving and thrill, and a continuous grade $4 / 6$ murmur at the left parasternal border. The electrocardiogram (ECG) exhibited a normal sinus rhythm, left ventricular hypertrophy, and no arrhythmia. The chest film exhibited mild cardiomegaly with increased pulmonary blood flow. Transthoracic and transesophageal echocardiography revealed an aortic-right ventricular fistula diagnosed as tubular type fistula due to a ruptured sinus of Valsalva. The fistula was 3 millimeters $(\mathrm{mm})$ in diameter. In addition, the following features were observed: left to right flow, pressure gradient $100 \mathrm{mmHg}$, good LV function, ejection fraction $70.0 \%$, and right ventricular systolic pressure 40 millimeters of mercury $(\mathrm{mmHg})$ [systolic blood pressure (SBP) $120 \mathrm{mmHg}$ ] (Figure 1). After counseling, the parents provided informed consent for transcatheter closure of the defect. The procedure was performed under general anesthesia and intubation. Transesophageal echocardiography (TEE) and A biplane aortography were performed and revealed a ruptured sinus of Valsalva 3 $\mathrm{mm}$ from the aorta to the right ventricle chamber with a normal right coronary artery (Figure 2). Right, and left heart catheterization revealed a pulmonary arterial pressure
(PAP) that was $30.0 \%$ of SBP, a pulmonary: systemic blood flow ratio of 1.3:1, pulmonary vascular resistance of 0.2 Wood units. $\mathrm{m}^{2}$, pulmonary vascular resistance: systemic vascular resistance ratio of $0.1: 1$, and left ventricular end-diastolic pressure of $13 \mathrm{mmHg}$. An Amplatzer Duct Occluder II (ADO II) size 4/4 was chosen. After the defect was crossed with a 5-French Judkins right guiding catheter (Cordis), a Terumo wire was snared in the main pulmonary artery and brought down to the femoral vein to form an arteriovenous loop. The delivery sheath (Torque Vue ${ }^{\mathrm{TM}}$ sheath, The AmplatzerTMduct occluder II (ADO II Abbott, Plymouth, MN, United States of America) was inserted through the femoral vein and advanced along the wire to the right ventricle and passed through the ruptured sinus of Valsalva. The system was moved together until the delivery sheath reached the ascending aorta. The distal disk and body of the device were deployed. The system was slowly retracted until the distal disc conformed to the aortic cusp. The proximal disk was then deployed in the right ventricle. Distal disc placement was confirmed with TEE and fluoroscopy. The post-deployment angiogram revealed a well-seated device without residual shunt and no entrapment of the aortic valve or right coronary artery. After the position was satisfactory, the device was released (Figure 3).

\section{Discussion}

Congenital aortic-right ventricular fistula is a rare condition. The cause of the fistula is not clear. However, some study reveals the aortic media incomplete fusion of distal bulbar septum and truncal ridges that there is resulting in an abnormal fusion of the aortic media and fibrosis of the aortic valve. ${ }^{3}$ These fistulas have been reported from trauma such as in penetrating chest injuries. ${ }^{4}$ An aortoright ventricular fistula must be distinguished from the aortic-ventricular tunnel located in the tunnel lie above the right sinus of Valsalva. In this case, the fistula always 


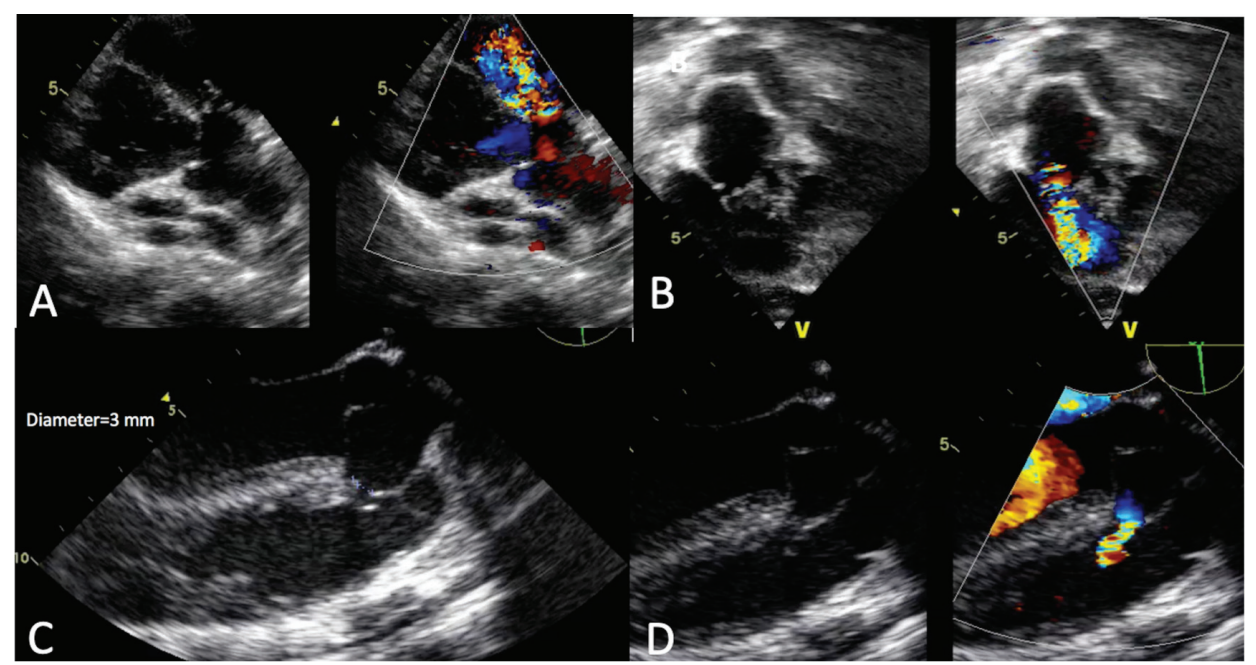

$\mathrm{mm}=$ millimeter

Figure 1 A-B: Transthoracic echocardiogram showing fistula jet from aorta to right ventricle;

C-D: Transesophageal echocardiogram showing fistula jet from aorta to right ventricle; diameter $4 \mathrm{~mm}$

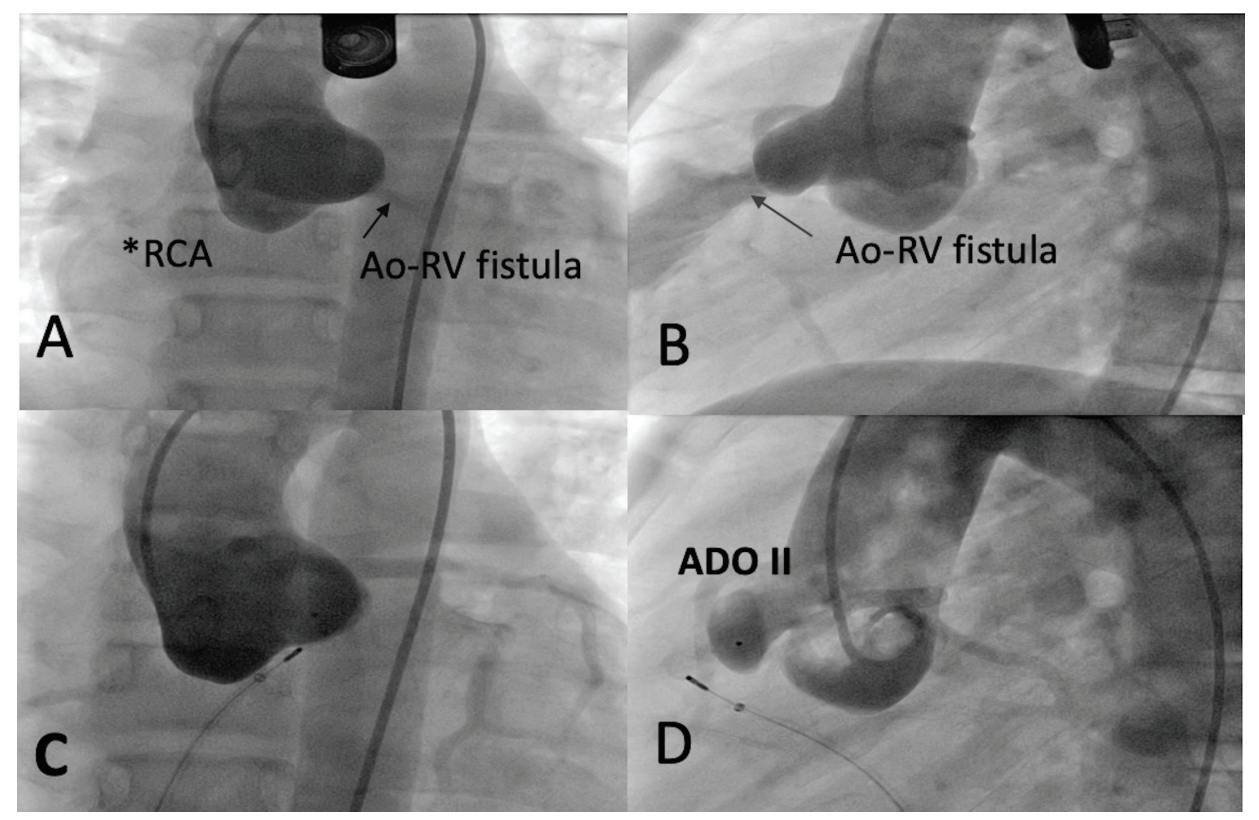

Ao-RV fistular=aortic-right ventricular fistula, RCA=right coronary artery, ADO II=Amplatzer Ductal Occluder II

Figure 2 A-B: Aortic root angiography revealed aortic right ventricular fistula with normal right coronary artery

C: Angiography during deployment of ADO II in fistula

D: Angiography shows well-seated device without the residual shunt and no obstruction of the RCA 


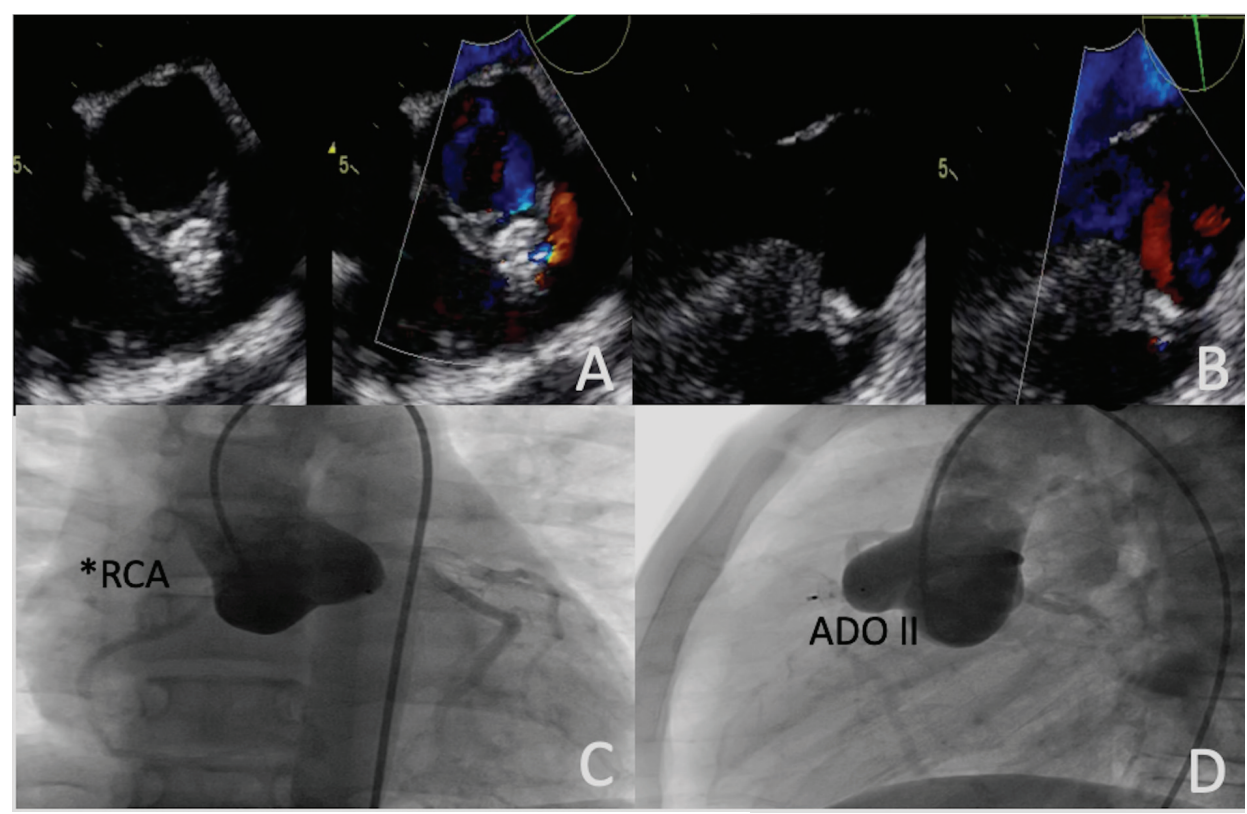

RCA=right coronary artery, ADO II=Amplatzer Ductal Occluder ॥

Figure 3 A-B: TEE with color flow Doppler of the ADO II after deployment shows no residual shunt

C-D: Angiography shows well seated device without residual shunt and no obstruction of the RCA

communicates between the right sinus of Valsalva with the right ventricular chamber. ${ }^{5}$ There has been associated with other congenital defects, for instant, ventricular septal defects, aortic insufficiency, bicuspid aortic valves, and persistent left superior vena cava. ${ }^{6,7}$ The symptoms are variable, acute heart failure or may have insidious $\mathrm{CHF}$ with aortic regurgitation lesion that depending on the site of rupture. ${ }^{7}$ In addition, identification of the coronary artery is a crucial thing before a definite diagnosis. We use transthoracic echocardiography for diagnosis which a parasternal long-axis view with clockwise rotation of the probe demonstrates the real tunnel, as well as its aortic origin and right ventricular opening. ${ }^{8}$ Open heart surgery is needed to correct the lesion in past and surgical repair with cardiopulmonary bypass has been performed since 1957. ${ }^{9}$ Nowadays, percutaneous transcatheter closure of an aortic ventricular fistula has recently produced good results over open surgical repair. ${ }^{10}$ Percutaneous closure of the defect has been reported by Cullen et al. ${ }^{11}$ in 1994 , in a patient with recurrent disease after prior surgical repair using the Rash- kind umbrella. Fedson et all have published that using Amplatzer duct occluder which is a device undergoing clinical trials for the closure of patent ductus arteriosus however, the ADO I should place in sited of rupture because of the device has been a risk of interfering with the cusps of the aortic valve. ${ }^{12}$ In our case, the transesophageal echocardiography and fluoroscopy were used to guide the procedure. We selected a device with a waist that was 1-2 $\mathrm{mm}$ larger than the defect size and selected the shortest length. The ADO II is specially designed for a small patent ductus arteriosus. However, we used it for an aortic-right ventricular fistula given that the ADO II has a low profile and is flexible and easy to deliver. Moreover, the device can be used for a retrograde 
technique (no need to create an arteriovenous loop) given that the fluoroscopic time was short and there was no entrapment of adjacent organs. The ADO II can be used for device closure in a small fistula and is easier than previous procedures.

\section{Conclusion}

An aortic-right ventricular fistula was successfully closed with an ADO II. The ADO II is a good choice for a small left to right shunt fistula. We selected the device with a waist that was 1-2 $\mathrm{mm}$ larger than the defect size and used the shortest length.

\section{Conflict of interest}

The authors have no conflicts of interest to report.

\section{References}

1. Miller DL, Morris JJ, Schaff HV, Mullany CJ, Nishimura RA, Orszulak TA. Reoperation for aortic valve periprosthetic leakage: identification of patients at risk and results of operation. J Heart Valve Dis 1995;4:160-5.

2. Pilgrim T, Meier B, Wenaweser $P$. Aorto-right ventricular fistula after transfemoral aortic valve implantation. J Invasive Cardiol 2010;22:E30-1.

3. Edwards JE, Burchell HB. The pathological anatomy of deficiencies between the aortic root and the heart, including aortic sinus aneurysms. Thorax 1957;12:125-39.
4. Rustad DG, Hopeman AR, Murr PC, Van Way CW. Aortocardiac fistula with aortic valve injury from penetrating trauma. J Trauma 1986;26:266-70.

5. Davis JA, Cecchin F, Jones TK, Portman MA. Major coronary artery anomalies in a pediatric population: incidence and clinical importance. J Am Coll Cardiol 2001;37:593-7.

6. Yildirir A, Batur MK, Kabakci G. Ruptured aneurysm of the sinus of valsalva in association with persistent left superior vena cava--a case report. Angiology 2000;51:167-71.

7. Choudhary SK, Bhan A, Sharma R, Airan B, Kumar AS, Venugopal P. Sinus of Valsalva aneurysms: 20 years' experience. J Card Surg 1997;12:300-8.

8. Arora R, Trehan V, Rangasetty UMC, Mukhopadhyay S, Thakur AK, Kalra GS. Transcatheter closure of ruptured sinus of valsalva aneurysm. J Intervent Cardiol 2004;17:53-8.

9. Barragry TP, Ring WS, Moller JH, Lillehei CW. 15- to 30-year follow-up of patients undergoing repair of ruptured congenital aneurysms of the sinus of Valsalva. Ann Thorac Surg 1988; 46:515-9.

10. Khoury A, Khatib I, Halabi M, Lorber A. Transcatheter closure of ruptured right-coronary aortic sinus fistula to right ventricle. Ann Pediatr Cardiol 2010;3:178-80.

11. Cullen S, Somerville J, Redington A. Transcatheter closure of a ruptured aneurysm of the sinus of Valsalva. Br Heart J 1994;71: 479-80.

12. Fedson S, Jolly N, Lang RM, Hijazi ZM. Percutaneous closure of a ruptured sinus of valsalva aneurysm using the amplatzer duct occluder. Catheter Cardiovasc Interv Off J Soc Card Angiogr Interv 2003;58:406-11. 